\title{
The syndrome of inappropriate antidiuresis: a diagnosis of exclusion for euvolemic hyponatremia
}

\author{
Hiroshi Ito ${ }^{1}\left[\right.$. Ryoko Ogawa ${ }^{1}$
}

Received: 5 December 2021 / Accepted: 13 December 2021 / Published online: 18 January 2022

(c) The Author(s), under exclusive licence to Springer Nature B.V. 2021

\section{Editor,}

According to Bilgetekin and colleagues, tolvaptan effectively reduced the length of hospital stay in cancer patients with hyponatremia [1]. Hyponatremia in such patients is often caused by the syndrome of inappropriate antidiuretic hormone (SIADH) due to the ectopic production of vasopressin [2]. Recent studies have suggested the effectiveness of tolvaptan for SIADH, and this study seems to add some insights into this context [3]. However, we would like to raise one critical issue: the complexity of SIADH diagnosis.

The differential diagnosis of hyponatremia is based on fluid status [4]. For example, hypervolemic hyponatremia includes heart failure, cirrhosis, and renal failure. On the other hand, hypovolemic hyponatremia includes vomiting, diarrhea, diuretic use, and cerebral salt wasting syndrome. SIADH is well known to be classified as euvolemic hyponatremia. However, other causes of euvolemic hyponatremia include adrenal and pituitary insufficiency and hypothyroidism. Because these endocrine diseases sometimes result in reduced circulation and subsequent shock, thoughtless use of diuretics, including tolvaptan, in patients with euvolemic hyponatremia can be unsafe.

Furthermore, the diagnosis of SIADH also requires high serum osmolality ( $>100-150 \mathrm{mOsm} / \mathrm{kg}$ ), inadequate to low serum osmolality, and natriuria $(>30 \mathrm{mmol} / \mathrm{L})$ with normal dietary salt and water intake. Other minor criteria for SIADH diagnosis include high fractional excretion of sodium, high fractional excretion of urea, failure to correct hyponatremia after $0.9 \%$ saline infusion, and correction of hyponatremia through fluid restriction.

Although it seems complicated to include patients according to the Schwartz and Bartter criteria for SIADH due to the

Hiroshi Ito

itohirokan@yahoo.co.jp

1 Division of Hospital Medicine, University of Tsukuba Hospital, 2-1-1 Amakubo, Tsukuba, Ibaraki 305-8576, Japan retrospective nature of this study [5], the authors should have at least excluded the possibility of other endocrine diseases in these patients. Thus, we should consider the limitation of hyponatremia diagnosis when interpreting the results of this study.

Funding This research received no specific grant from any funding agency in the public, commercial or not-for-profit sectors.

\section{Declarations}

Conflict of interest None of the authors have any conflicts of interest to disclose.

\section{References}

1. Bilgetekin I, Erturk I, Basal FB, Karacin C, Karadurmus N, Oksuzoglu B, Demirci U (2021) Tolvaptan treatment in hyponatremia due to the syndrome of inappropriate secretion of antidiuretic hormone (SIADH): effects on survival in patients with cancer. Int Urol Nephrol 53:301-307. https://doi.org/10.1007/ s11255-020-02623-7

2. Berardi R, Rinaldi S, Caramanti M, Grohè C, Santoni M, Morgese F, Torniai M, Savini A, Fiordoliva I, Cascinu S (2016) Hyponatremia in cancer patients: time for a new approach. Crit Rev Oncol Hematol 102:15-25. https://doi.org/10.1016/j.critrevonc.2016.03. 010

3. Kleindienst A, Georgiev S, Schlaffer SM, Buchfelder M (2020) Tolvaptan versus fluid restriction in the treatment of hyponatremia resulting from SIADH following pituitary surgery. J Endocr Soc. https://doi.org/10.1210/jendso/bvaa068

4. Lee JJ, Kilonzo K, Nistico A, Yeates K (2014) Management of hyponatremia. CMAJ 186:E281-E286. https://doi.org/10.1503/ cmaj. 120887

5. Pillai BP, Unnikrishnan AG, Pavithran PV (2011) Syndrome of inappropriate antidiuretic hormone secretion: revisiting a classical endocrine disorder. Indian J Endocrinol Metab 15:S208-S215. https://doi.org/10.4103/2230-8210.84870

Publisher's Note Springer Nature remains neutral with regard to jurisdictional claims in published maps and institutional affiliations. 